\title{
Theologie en Religiewetenschappen - een positiebepaling
}

Over de verhouding van de theologie tot de religiewetenschappen wordt sedert geruime tijd hevig gestreden. Deze strijd kan niet enkel herleid worden tot een wetenschapstheoretisch geschil of op een geschil omtrent de epistemologische status van beide disciplines, ondanks het feit dat de strijd ook hierover gaat. De klaarblijkelijke nervositeit waarmee het debat vooral aan de kant van de theologie wordt gevoerd, signaleert namelijk ook een statusprobleem of een academisch machtsprobleem - een gevecht om 'symbolisch kapitaal' (Pierre Bourdieu). En dit probleem is op zijn beurt de uitdrukking van een maatschappelijk en een cultureel probleem. In deze afhandeling zal ik verschillende aspecten van het debat proberen te onderscheiden om op deze manier een vernauwing of een eenzijdige benadering te vermijden.

\section{Actuele schermutselingen}

Dit artikel werd geschreven enkele dagen na het hoogtepunt van de commotie omtrent de opheffing van de excommunicatie van het reactionaire en antisemitische, antimoderniteitsgerichte en totalitaire Pius X-broederschap door het Vaticaan. Vooral in Duitsland hebben theologen van verschillende faculteiten zoals die van Münster, Tübingen, Freiburg en Würzburg een petitie ondertekend waarin zij protesteren tegen deze gang van zaken en hun zorg over ontwikkelingen in de Rooms-Katholieke Kerk articuleren. Dit deden ook enkele theologen van de faculteit van de Universiteit Regensburg, de vroegere faculteit van Josef Ratzinger. Vandaag, 17 februari 2009, lees ik in de

Süddeutsche Zeitung dat Gerhard Lüdwig Müller - de bisschop van Regensburg - van plan is om sancties tegen de ondertekenaars te nemen. Hij is van mening dat deze theologen de paus hebben beledigd en dat zij nu publiekelijk hun excuus moeten aanbieden. Binnen twee weken moeten zij bovendien in het bijzijn van de bisschop de geloofsbelijdenis uitspreken en een eed van trouw op de leer van de Katholieke Kerk afleggen als 'teken van de erkenning van het leerambt'. Müller heeft de brief, waarin hij aan de theologen deze disciplinerende maatregel oplegt, tevens aan de prefect van Congregatie van het Geloof (de voormalige Inquisitie) en aan diverse andere kerkelijke instanties verstuurd. Indien de theologen niet gehoorzamen, worden verdere acties aangekondigd. Dit laatste betekent dat zij hun 'mandatum docendi' zullen verliezen. Dit incident werpt een helder licht op de academische status van de (katholieke) theologie: Van theologen wordt verwacht 
dat zij noch in onderwijs noch in onderzoek afwijken van de kerkelijke leer. Door gebruik te maken van het vrije woord of zoals in dit geval door publiekelijk kritiek aan het Vaticaan te uiten hebben zij in de bisschoppelijke perceptie hun academisch ambt misbruikt, terwijl men toch zou vermoeden dat zij juist een goed gebruik van dit ambt hebben gemaakt omdat de academie als geen ander de thuishaven van het vrije woord is.

Dezer dagen wordt een ander conflict over de vrijheid van de theologische wetenschap opgelost. De bekende Duitse protestantse exegeet Gerd Lüdemann werd enkele jaren geleden gedwongen om zijn leerstoel te verlaten, omdat hij zich op een bepaald moment als 'niet meer gelovige' had bekend. Het ministerie van wetenschappen was en is van mening dat het 'kerkelijke recht op autonomie' voorrang geniet op de vrijheid van de wetenschap van een hoogleraar! (Süddeutsche Zeitung, 19.2.09)

Zonder twijfel bestaat er dus een fundamenteel verschil in de opvattingen over de universiteit of de academie. Wat aan de ene kant als een forum van onbegrensde discussie wordt gezien - Jacques Derrida sprak over de 'onvoorwaardelijke vrijheid van het vragen en van de expressie' en van het 'recht om in de openbaarheid te spreken' ${ }^{1}$ die het wezen van de universiteit uitmaken -, wordt aan de andere kant als een pervertering van een ambt, van het ambt van de theologische wetenschapper, beschouwd dat blijkbaar de taak heeft de (katholieke) waarheid te bevestigen en niet te bekritiseren. Misschien is men geneigd dit conflict uitzonderlijk te vinden en dus niet als representatief voor de academische theologie. Feitelijk klopt dit. Maar afgezien van enkele uitzonderingen kan er zelfs in het geval van de universitaire theologie geen sprake zijn van een de iure vrije wetenschap. Dit werpt de dramatische vraag op of een niet-vrije wetenschap nog wetenschap kan worden genoemd en niet beter ideologie. Het conflict van Regensburg geeft in extremis aan wat de wetenschapsjuridische status van de theologie is - haar afhankelijkheid van universiteitsexterne instanties. Talloos zijn de botsingen tussen universitaire theologie en kerkelijke controles en selectieprocedures. Bovendien wordt de afhankelijkheid of de binding van de theologie aan kerkelijke instanties niet zelden ook nog theologie-intern gelegitimeerd. Het conflict van Regensburg is dus geen anomalie: van katholieken en dus a fortiori van katholieke theologen wordt gehoorzaamheid verwacht, 'gehoorzaamheid van de wil en van het inzicht'. In protestantse milieus komt men zulke grove verwachtingen minder

1 Jacques Derrida, Die unbedingte Universität, Frankfurt am Main 2001, 10. 
vaak en natuurlijk in andere bewoordingen tegen. Het duplex-ordo-model geeft echter ook op zijn beurt aan hoe lastig de gewone academische status van de theologie te verdedigen is.

\section{Wie wenst wat te zijn? Een radicale transformatie}

Theologen vinden het in toenemende mate geen probleem wanneer zij religiewetenschapper worden genoemd. Maar religiewetenschappers zullen zich met hand en tand verzetten wanneer zij als theologen moeten fungeren. Theologisch onderzoek kan in nogal wat disciplines als religiewetenschappelijk onderzoek worden bestempeld of als taalwetenschappelijk, historiografisch, cultuurhistorisch of hermeneutisch onderzoek. Maar ik ken geen religiewetenschappelijk onderzoek dat het zou accepteren onder de noemer van theologisch onderzoek te worden gerubriceerd. Naarmate het wetenschappelijk karakter van de theologie meer in twijfel wordt getrokken omwille van het de iure beladen hypothesenprofiel van de theologie, zullen theologen er toe neigen hun onderzoek als krypto-religiewetenschappelijk in te schatten of het zelfs uitdrukkelijk als eigenlijk religiewetenschappelijk te herdefiniëren. Het is niet al te moeilijk om dit fenomeen te verklaren. In de canon van de universitaire wetenschappen heeft de theologie een problematische status, om het voorzichtig uit te drukken. Niets infecteert de wetenschapsstatus van een bepaalde discipline meer dan de verdenking dat wetenschappers niet vrij kunnen opereren. Het vaak te horen tegenargument dat ook in andere wetenschappen externe - politieke of industriële - invloeden een rol spelen, kan natuurlijk niet overtuigen, want hier wordt het ene kwaad door het andere uitgedreven. Bovendien is theologisch onderzoek tijdens de voorbije decennia daadwerkelijk aan radicale transformaties onderworpen geweest die tot gevolg hebben gehad dat het theologische van de theologie niet zelden zoek is geraakt. Jan Platvoet stelt daarom terecht de vraag of het niet eerlijker zou zijn in nogal wat gevallen van theologisch onderzoek gewoonweg van 'godsdienstwetenschap [of religiewetenschap] van het christendom' te spreken. Platvoet noemt deze theologie 'gedetheologiseerde theologie' ${ }^{2}$ en hij doet dit opnieuw terecht.

Deze analyse wordt vaker gesteld. In een interessante bijdrage mit de titel 'Theologie als christliche Religionskulturwissenschaft' heeft de bekende Duitse filosoof Hermann Lübbe enkele jaren geleden een vlijmscherpe

2 Zie het artikel van Jan G. Platvoet in dit nummer. 
diagnose over de toestand van de theologie gesteld. Lübbe vertrekt vanuit de vaststelling dat veranderingen in de theologie altijd (ook) het gevolg van maatschappelijk-culturele transformatieprocessen zijn geweest. Wij spreken hier natuurlijk niet over de samenhang tussen actuele maatschappelijke en culturele vraagstukken en theologische commentaren op deze processen. Het gaat veelmeer over het profiel van de theologie als gevolg van culturele veranderingen in de 'longue durée'. In de loop van de (westerse) moderniteit, zo luidt de stelling van Lübbe, is het christendom in toenemde mate geen Herkunftswelt, geen 'wereld van afkomst' meer. Ondanks alle historische interdependenties tussen het christendom en Europa kan er vandaag geen sprake meer van zijn dat Europa zich situeert in de normatieve horizon van het christendom als een exemplarische en dus bindende religieuze factor. Voor ons - zo Lübbe - is het christendom een Vergangenheitswelt, een 'verleden wereld' geworden. Of anders geformuleerd: wat ooit zonder veel moeite als onze normatieve afkomst werd beschouwd en een verplichtende invloed op ons doen en laten, op ons zelfbegrip en onze wereldvisie had, is nu een wereld van het (interessante) verleden. Men zou dit ook als het historisch worden van het christendom kunnen typeren of zelfs als zijn musealisering. Natuurlijk wil Lübbe niet beweren dat het christendom als een geleefde religie nog slechts een marginaal fenomeen zou zijn, alhoewel de ontchristelijking in tal van Europese landen sterk in deze richting tendeert. Talrijke mensen bekennen zich tot het christendom als een belangrijke factor in hun leven en zij gebruiken vaak woorden zoals 'zingeving' of 'betekenisgeving' wanneer zij over hun christelijke identiteit spreken. Het is echter juist dit vocabulair dat de these van Lübbe lijkt te bevestigen. Het christendom als 'zin' is slechts een afkooksel van de kosmologische, geschiedenistheologische, handelingsaansturende, eschatologische en liturgische commentaren en geloofsartikelen die dit zelfde christendom over de totaliteit van de dingen ooit durfde en kon formuleren. Cultureel is het christendom vandaag minoritair geworden en het christelijke zelfbegrip van Europa is uitermate selectief en precair geworden.

De transformatie van het (westerse) christendom van een 'wereld van afkomst' naar een 'verleden wereld' maakt deze religie natuurlijk niet minder interessant. In tegendeel. Een interessante religie is alleen iets helemaal anders dan een verplichtende religie. Een interessante religie kan rekenen op een cultuurhistorische aandacht, op een esthetische aandacht. Maar interessante religies zijn religies op afstand. De theologische zelfarticulatie van het christendom wordt nu op haar beurt getransformeerd in een 'religiecultuurwetenschappelijke' (Lübbe) of in een 'cultuur-historiografische' benadering. Publicaties die aspecten van het christendom vanuit dit perspec- 
tief benaderen, kunnen rekenen op een grote belangstelling, terwijl theologische publicaties in kleine oplagen onder het stof komen. De theologie is inmiddels in grote mate zelf cultuurwetenschappelijk en historiografisch geworden. Of zoals Lübbe het uitdrukt: 'Theologie is de methodisch gedisciplineerde cultuurhistorische presentatie van de christelijk-religieuze culturele geschiedenis waarvan wij afkomstig zijn. ${ }^{3}$ Met de protestantse theoloog en historicus Friedrich Wilhelm Graf kan men het nog korter formuleren: theologie is inmiddels 'cultuurwetenschap van het christendom'. ${ }^{4}$ Het is de moeite waard om het citaat van Lübbe nog eens nauwkeurig te bekijken. Voorafgaand aan een commentaar moeten wij echter eerst de transformaties van de theologie nog beter in kaart brengen.

\section{Wat is er met de theologie gebeurd?}

Theologie is geen gegeven dat met het fenomeen religie intrinsiek verbonden is. Dit heeft met het feit te maken dat er in tal van religies geen 'leer van god' kan bestaan omdat deze religies geen godsdiensten in de letterlijke zin van het woord zijn. 'God' is geen universeel religieus begrip. Theologie is in hoge mate met de monotheïstische religies verbonden. In het jodendom, in het christendom en in de islam - hoe verschillend hun theologieën er ook mogen uitzien - kan daadwerkelijk sprake zijn van een permanente en systematische reflectie op de thema's, overtuigingen (beliefs), rituele praktijken en handelingen van de godsdienst. De alliantie van de articulatie van de belijdenis met wetenschapsparadigma's van de Antieke Oudheid, vooral van de Griekse filosofie, kenmerkt vooral (maar lang niet uitsluitend) in het christendom het ontstaan van een theologie, die een wetenschapskarakter heeft en sedert haar prille ontstaan de waarheid van het christendom wil (en moet) verdedigen. De klassieke formule luidt dat theologie het gevolg van een 'fides quaerens intellectum', van een 'geloof op zoek naar begrijpen' of een 'geloof op zoek naar inzicht' is. Reeds hier kan men op een uiterst simpele manier het verschil tussen theologie en religiewetenschap markeren: theologie is 'de leer van god'. Religiewetenschap is - zoals het woord ondubbelzinnig zegt 'wetenschap van de religie'. In de theologie als 'de leer van god' worden wij echter met een dubbelzinnige uitgangspositie geconfronteerd: 'God' is object of thema van de theologie, maar in iedere klassieke theologie wordt veel meer beweerd. De theologie is namelijk zelf een articulatie van het geloof. Daarom

\footnotetext{
3 Hermann Lübbe, 'Theologie als christliche Religionswissenschaft', in M. Krieg e.a. (red.), Universitas in theologia - theologia in universitate, Zürich 1997, 43-59, 44.

4 Friedrich Wilhelm Graf, Die Wiederkehr der Götter. Religion in der modernen Kultur, München 2004, 261.
} 
heeft de formule 'fides quaerens intellectum' een complexe betekenis: de theologie is niet het gevolg op afstand van het feit dat het geloof op zoek is naar inzicht. Zij beschrijft dus niet enkel deze zoektocht. Zij is zelf het geloof dat op zoek naar het begrijpen is. Theologie is dus de intellectuele zelfarticulatie van het geloof. Hoe men het ook draait of keert, de canon van alle klassieke theologische vakken is gebaseerd op deze vooronderstelling. De vakkencanon van de theologie wordt doordesemd door deze uitgangspositie. In de exegese, in de kerkgeschiedenis, in de dogmatische theologie of in de moraaltheologie - de demonstratio fidei of de apologie van het godsgeloof is het uiteindelijke doel van iedere (klassieke) theologie.

De lezer weet dat dit model sedert de Verlichting aan een geweldige erosie onderhevig is. Talrijk zijn de conflicten geweest tussen de normatieve of orthodoxe verwachtingen die men aan de theologie adresseert en haar feitelijke ontwikkelingen. Eerst in de exegese, maar dan 'peu à peu' in bijna alle vakken zijn er hevige spanningen ontstaan als gevolg van het feit dat de wetenschappelijke en 'methodisch gedisciplineerde' (Lübbe) manifestatie van de theologie onder de condities van de moderne wetenschapsparadigma's geen recht kan doen aan de verwachting dat zij de waarheid van het christendom moet demonstreren. Dit geldt overigens niet slechts voor de christelijke theologie. Ik geef een concreet voorbeeld: toen enige tijd geleden de islam-wetenschapper Muhammad Kalisch, die aan de universiteit van Münster in de opleiding van islamitische godsdienstleraren onderwijs verzorgde, publiekelijk duidelijk maakte dat hij ernstige wetenschappelijke twijfels heeft dat de profeet Mohammed daadwerkelijk zou hebben bestaan, ontstond er een enorme rel in de Duitse islamitische wereld. Omwille van de druk die enkele islamitische bonden uitoefenden moest Kalisch niet alleen vragen om politiebescherming maar werd hij uiteindelijk verwijderd uit het universitaire curriculum. $\mathrm{Nu}$ is Kalisch geen theoloog maar een jurist en religiewetenschapper, maar dit incident maakt opnieuw in extremis duidelijk hoe het met de academische vrijheid van het woord gesteld is wanneer de waarheidsaanspraken van een religie worden betwijfeld of aangetast. Ik probeer dit probleem wetenschapstheoretisch te vertalen.

Er bestaat geen enkele wetenschap die niet van een 'gestuurde' hypothese vertrekt. Iedere wetenschap heeft een interesse aan de juistheid van haar fundamentele vooronderstellingen omtrent een specifiek object of thema. Van deze hypothese moet tijdens het theoretische proces blijken dat zij als een zinvolle, operationaliseerbare en vruchtbare hypothese kan worden gehandhaafd. Iedere hypothese is juist voor de duur van haar wetenschappelijke 
maturiteit. Maturiteit betekent in dit geval dat de hypothese niet is weerlegd en dat het netwerk van argumenten dat de hypothese moet steunen coherent en consistent is. Een methodenpluralisme is daarbij een goede zaak: wetenschappen maken gebruik van verschillende methodes en zelfs binnen een bepaald wetenschapsgebied kunnen diverse methodes worden gemobiliseerd experimentele, empirisch-sociaalwetenschappelijke, kwantitatieve of kwalitatieve, hermeneutische, descriptieve of evaluatieve, analytische of transcendentale methodes etc. Twee elementaire vooronderstellingen moeten worden gehanteerd en wanneer één van deze ontbreekt, kan er sprake zijn van een ernstig probleem omtrent het wetenschappelijk karakter van een bepaalde discipline: iedere hypothese moet in principe weerlegd kunnen worden. Kan zij dat niet, kan er geen sprake zijn van een hypothese als wel van een dogmatisch uitgangspunt. Dat betekent dat niet-falsificeerbare uitgangspunten in feite wetenschappelijk oninteressant zijn omdat zij het wetenschapskarakter van ieder wetenschap vernietigen. Het tweede uitgangspunt betreft het verschil tussen methode en object van onderzoek. De methode is een hulpmiddel, een 'weg', die men moet bewandelen, om beter inzicht in het object van onderzoek te verkrijgen.

Natuurlijk leent niet ieder thema zich voor iedere methode (en omgekeerd). Het heeft bijvoorbeeld geen zin om op het veld van de dogmatiek een empirische falsificatie of verificatie na te streven. Toch moeten ook dogmatische stellingen falsificeerbaar zijn. 'Falsificeerbaar' betekent in dit geval niet dat het ongelijk van een dogma door een bewijs kan worden aangetoond, maar wel dat men tot de conclusie kan komen dat er geen overtuigende en coherente argumentatiestrategieën te vinden zijn. Men zou de eisen zelfs nog kunnen afzwakken door slechts te verlangen dat men de verkeerdheid van een hypothese uit de dogmatiek - dus van een christelijke dogma - niet a priori mag uitsluiten. Een uiterst centrale voorwaarde voor de mogelijke falsificeerbaarheid van een hypothese is nu juist het onderscheid tussen methode en object. Wie als antwoord op de vraag naar de methode van de theologie het antwoord geeft dat deze methode 'theologisch' is zal worden geconfronteerd met de verdenking dat het object hier de methode determineert. In dit geval zal de methode de juistheid van het object en dus ook van de hypothese alleen maar kunnen bevestigen. 'Theologische methodes van de theologie' zijn even onzinnig als 'psychologische methodes van de psychologie' etc. Wanneer de bevestiging van de hypothese de 
uitdrukkelijke doelstelling van een wetenschapsgebied wordt, is er iets grondig fout gegaan: uit een 'gestuurde hypothese' is een 'beladen hypothese' geworden. ${ }^{5}$ En de methode is geselecteerd op basis van de normatieve verwachting dat zij het object van de te verwerven kennis bevestigd. Ik herhaal: er bestaat een legitiem en zelfs noodzakelijk methodenpluralisme. En het is en kan niet de inzet van een wetenschap zijn haar hypothese te weerleggen. In tegendeel - iedere wetenschap wil juist de juistheid van haar hypothese aantonen. Maar zij kan deze juistheid slechts aantonen door haar object methodisch falsificeerbaar te houden. Wie dit niet kan, wil of mag, heeft geen wetenschappelijke ambitie en kan dus ook het predicaat 'wetenschap' niet opeisen.

In zijn bijdrage over 'De eigen vraaghorizon van theologie en godsdienstwetenschappen' in dit nummer heeft Andreas J. Beck terecht herinnerd aan de door Heinrich Scholz in Münster destijds geopperde (en door Karl Barth vehement bestreden) wetenschapseisen voor de theologie. Ik noem de vijf eisen, die ook voor onze discussie van het grootste belang zijn: het 'propositiepostulaat', het 'coherentiepostulaat', het 'controleerbaarheidspostulaat', het 'onafhankelijkheidspostulaat' en het 'concordantiepostulaat'. Voor alle postulaten geldt mijns inziens dat zij - zoals het door Wolfhart Pannenberg wordt verlangd - vanzelfsprekend ook voor de theologie gelden. Beck zelf markeert dat hij Pannenberg bijvalt 'voor zover hij de eis naar consistentie op het oog heeft', waarmee hij vermoedelijk het 'propositiepostulaat' meent, de 'expliciete formulering van de logische implicaties van assertieve proposities'. ${ }^{6}$ Consistentie is echter alleen maar een absoluut minimum. Ik chargeer nu weliswaar maar ook ideologieën kunnen absoluut consistent zijn. Consistentie is een vanzelfsprekend (en daarom bijna banaal) formeel-logisch postulaat zonder het welke ieder vertoog aan tegenspraken en logische fouten ten gronde gaat. Consistente beweringen zijn pas wetenschappelijk interessant wanneer zij op de een of andere manier controleerbaar zijn, coherent en onafhankelijk. Inderdaad kan voor een wetenschappelijke theologie 'god' slechts als probleem bestaan - als hypothese, die van op een methodische afstand onderzocht wordt. Beck diagnostiseert juist wanneer hij aan Pannenberg de vraag stelt of deze toch niet al te zeer vanuit de theologie

5 Zie Theo A.F. Kuipers, 'De logica van de G-hypothese. Hoe theologisch onderzoek wetenschappelijk kan zijn', in K. Hilberdink (red.), Van God los? Theologie tussen godsdienst en wetenschap, Amsterdam 2004, 59-74, 63.

6 Andreas J. Beck in dit nummer, p. 243. 
naar de religiewetenschappen kijkt wanneer deze vindt dat, zoals Beck samenvattend formuleert, 'de religieuze tradities worden getoetst aan de hand van de maatstaf van hun eigen verstaan van de goddelijke werkelijkheid'?

Men vraagt zich echter verbaasd af wat in het licht van deze formulering van het 'controleerbaarheids- en onafhankelijkheidspostulaat' over is gebleven. Kan er van toetsing van religies überhaupt nog sprake zijn wanneer deze geschiedt 'aan de hand van de maatstaf van hun eigen verstaan van de goddelijke werkelijkheid'? Dan zijn de recente gebeurtenissen rondom Muhammad Kalisch geen academisch schandaal maar een 'logische implicatie van de assertieve proposities' van de Islam. Anders geformuleerd: wanneer volgens Beck 'de goddelijke openbaring de norma normans van de christelijke theologie' betekent, ${ }^{8}$ zijn het controleerbaarheids- en onafhankelijkheidspostulaat verpulverd. Ik beweer hier geenszins dat het eigen verstaan van religie een quantité négligeable voor theologisch of voor religiewetenschappelijk onderzoek zou zijn. Het zou dwaas zijn dit eigen verstaan te verontachtzamen. Maar dit eigen verstaan kan toch niet de norma normans van het onderzoek zijn? Waarom zouden wij aan onderzoek willen doen wanneer het object van ons onderzoek zich aan de normen van wetenschap onttrekt en zijn eigen norm oplegt? Wat valt er dan nog te onderzoeken?

Beck modificeert verderop in zijn bijdrage zijn standpunt door ook de postulaten van de controleerbaarheid en de coherentie voor de theologie te reclameren. Hij wil zelfs tegemoet komen aan een soft-version van het methodologische agnosticisme. Deze zachte versie vraagt aan de theoloog om in zijn respectievelijke deeldiscipline geen beroep te doen op 'goddelijke inspiratie', op de 'vinger van God' of op een 'goddelijk ingrijpen'. De epoche, het methodologische tussen haakjes zetten van deze religieuze termen geldt echter niet voor 'het fundamentele vertrekpunt in het geloof'. ${ }^{9}$ De argumenten van Beck die hier ter verdediging van het standpunt gemobiliseerd worden, kunnen echter niet overtuigen. 'Rigide en legitiem denken en argumenteren houdt niet op wetenschappelijk te zijn omdat vanuit een bepaalde geloofsopvatting wordt gestart.' Maar dat zal ook niemand serieus willen betwijfelen. Waarom zou de theoloog zijn persoonlijke geloofsopvatting in het

\footnotetext{
7 Beck in dit nummer, p. 243.

8 Beck in dit nummer, p. 244.

9 Beck in dit nummer, p. 246.
} 
theologische discours niet willen bevestigen? Waarom zou hij niet mogen starten met deze hoop? Ook een hersenwetenschapper moet de opvattingen die hij heeft omtrent bepaalde hersenfuncties en die hij intuïtief juist vindt en graag bevestigd wil zien toch niet opgeven vooraleer aan het onderzoek te beginnen? Maar wetenschap wordt een farce wanneer de geloofsopvatting, de openbaring, het bestaan van god als norma normans of een hersenfunctie niet weerlegd mag worden.

Ook het volgende argument van Beck moet ik betwisten. 'Een volstrekt neutraal of objectief standpunt is immers een illusie en zou overigens ook onleefbaar zijn.' Maar in welke serieuze wetenschap wordt volstrekte neutraliteit of objectiviteit als een ideaal geprezen? Serieuze wetenschap heeft kennis van het vooroordeelskarakter van iedere beginnende verkenning van een bepaald thema of object. In de hermeneutische cirkel wordt recht gedaan aan het feit dat ieder poging om een fenomeen te verstaan met een voorverstaan begint. Dit voorverstaan kan een meer informatief karakter hebben men moet reeds iets weten om te kunnen vragen en verder te kunnen weten. Dit voorverstaan kan ook een meer existentieel karakter hebben. Men moet een dieper liggende interesse hebben om voldoende gemotiveerd te zijn voor het wetenschappelijke arbeiden aan een thema of object. Echter, de in dit verband vaak aangehaalde 'Horizontverschmelzung' (Hans Georg Gadamer) betekent natuurlijk niet dat het thema alleen maar bevestigd kan worden. De horizon van de uitgangspositie - die van de start - kan in de ontmoeting met het thema of het object verregaand intact blijven. Maar dit hoeft niet zo te zijn.

'Horizontverschmelzung' kan ook betekenen dat de startpositie - het vooroordeel - helemaal niet bevestigd wordt. Voor iedere wetenschap geldt dat zij vanuit een 'principle of charity' moet willen vertrekken, vanuit de presuppositie dat het object of het thema een redelijke toegang veroorlooft en toelaat. Men gaat er van uit dat het object begrepen kan worden, dat het een redelijke structuur bezit. ${ }^{10}$ Anders hoeven we niet te beginnen. Maar wetenschap (in de meest brede zin van het woord) valt en staat met een methodenbewustzijn en met het behartigen van basispostulaten, waarvan Beck er enkele heeft genoemd. Hij heeft gelijk wanneer hij tegen deze achtergrond het verschil tussen buiten- en binnenperspectief of dat tussen een 'etic analysis' en een 'emic analysis' als een duale kwalificatie voor religieweten-

10 Zie: Jean-Pierre Wils, Nachsicht. Studien zu einer ethisch-hermeneutischen Basiskategorie, Paderborn 2006. 
schap enerzijds (als 'etic analysis') en voor theologie anderzijds (als 'emic analysis') relativeert. Ook de religiewetenschap heeft het 'emic perspectief' nodig, reconstrueert dit echter vanuit een 'etic standpunt'. Ook de theologie heeft een 'etic perspectief' nodig, maar keert uiteindelijk terug naar haar uitgangspunt, naar het 'emic standpunt'. De beslissende vraag is echter hoe zij dit doet. Wanneer zij deze terugkeer wenselijk of mogelijk vindt, kan zij wetenschap zijn - voorondersteld dat zij methodische keuzes maakt, de basispostulaten van de wetenschap respecteert en dus de falsificatie van het uitgangspunt in principe toelaat. Wanneer zij de (bevestigende) terugkeer naar het 'emic perspectief' noodzakelijk of verplichtend vindt, is theologie van ideologie niet meer te onderscheiden.

\section{Opnieuw een perspectief op transformaties}

In het geval dat wij de theologie een zelfreflectie van religie in de vorm van een theorie zouden noemen, gaat het om een zelfbegrip van de eerste orde. Dat wil zeggen dat theologie hier de waarheidsclaim van een religie - op het niveau van de orthodoxie en van de orthopraxie - reflexief articuleert. Theologie ligt dan in het directe verlengde van deze waarheidsbewering. De waarheid van deze religie is dan de normatieve vooronderstelling van een theorie, respectievelijk van de theologie die dus van haar kant de begrippelijke en normerende expressie is van de waarheidsbewering van de religie in casu. Een reflectie van de tweede orde ontstaat op het moment dat de theologie zich als een nadenken over de zelfreflectie van een religie gaat ontwikkelen. De teksten van de theologie van de eerste orde worden nu het thema van een verdere begrippelijke en wetenschappelijke toetsing. In de theologie poogt men dan de theologie te begrijpen. Systeemtheoretisch uitgedrukt: terwijl in het zelfbegrip van de eerste orde een religie zichzelf cognitief bekijkt, wordt in het zelfbegrip van de tweede orde de theologie door de theologie bekeken. In feite tekenen er zich nu drie waarheidsniveaus af: de geleefde waarheid of de performatieve waarheid van de religie; de explicatieve waarheid van de religie op het theologische theorieniveau van de eerste orde; de epistemische waarheid van een religie op het theorieniveau van de tweede orde, waar de theologische meta-theorie zich richt op de theologie of op de textuele reflectie van de voorgaande orde. Er is dus sprake van een permanente aanwas van theorie. Dit heeft natuurlijk tot gevolg dat tussen de geleefde waarheid van een religie in het bewustzijn van de gelovigen en de huidige theologie een steeds grotere afstand groeit. Met Platvoet kan men hier ook spreken van de 
'geloofsondermijnende werking van de theologie zelf" ${ }^{11}$ of - minder dramatisch uitgedrukt - van het onverschillig worden van de theologie voor de geleefde waarheid van de religie (en omgekeerd). De impasse die nu ontstaat kan men als volgt karakteriseren: wil de theologie haar wetenschappelijke ambitie verdedigen, moet zij zich aan de progressieve rationalisering onderwerpen, die typisch is voor alle hedendaagse wetenschappen. Maar daardoor groeit de kloof tussen deze theologie en de performative waarheid van de religie. Wil de theologie echter vooral de explicatieve waarheid van de geleefde religie belichamen en dus zo dicht mogelijk bij de leefwereld van haar thematiek blijven, dreigt ze haar epistemische waarheid te torpederen. Deze dynamiek is niet theologie-typisch. Zij is op nagenoeg alle 'humanities' van toepassing. Opnieuw wordt echter duidelijk dat theologie geen symbiotische verhouding met haar thematiek of object kan hebben, wil zij wetenschap zijn.

\section{Hoe verder?}

Keren wij terug naar de in het begin van deze uiteenzetting gebruikte simpele karakteriseringen van theologie en religiewetenschap. Theologie werd daar 'de leer van god' genoemd. Religiewetenschap heette even simpel de 'wetenschap van de religie'. Wat de thema's betreft, is de religiewetenschap veel breder dan de theologie. Het verschil tussen theologie en religiewetenschap schijnt dan op een elegante manier te zijn opgelost. Zij hebben verschillende thema's. Toch is deze oplossing slechts een pragmatische oplossing, misschien zelfs een schijnoplossing. Verschillende thema's hebben namelijk niet 'per se' verschillende wetenschapsgebieden tot gevolg. Eén thema kan zich over verschillende wetenschappen uitspreiden en aanleiding geven tot nieuwe wetenschapsclusters. De menselijke taal bijvoorbeeld is achtereenvolgens het thema van de filosofie, van de linguïstiek, van de cultuurwetenschappen en van de hersenwetenschap geworden. Toch is de dominante rol van het thema voor de constitutie van een wetenschapsgebied niet te onderschatten. Om bij het laatste voorbeeld te blijven: de taal heeft zich in de loop van de moderne wetenschapsgeschiedenis langzaam maar zeker aan haar filosofische inkadering onttrokken, heeft een niet-filosofische, linguïstische benadering gekregen en recentelijk zijn er omtrent het thema taal nieuwe wetenschapsgebieden ontstaan - de neuro-linguïstiek met haar vertakkingen in de antropologie, de etologie of de zoölogie. Nieuwe wetenschapsclusters

11 Platvoet in dit nummer, p. 229. 
zijn het logische gevolg van de evolutie van de wetenschap als dusdanig. Dit is ook op de theologie, respectievelijk op haar verhouding tot de religiewetenschap van toepassing. De religiewetenschap is sedert het begin van de negentiende eeuw langzaam uit de theologie weggegroeid. Beslissend in dit proces was de distantiëring van de orthodoxie-verwachting van de theologie. Religie werd nu een thema dat zich mocht onttrekken aan het zelfbegrip van een particuliere confessie of aan het zelfbegrip van een particuliere religieuze praktijk. De thematisering van religie ging nu allianties aan met diverse methoden van de antropologie tot en met de psychoanalyse, van de sociologie tot en met de taalwetenschap, van de historiografie tot en met diverse andere cultuurwetenschappen. Maar deze zelfde ontwikkeling voltrok zich tevens in verschillende disciplines van de theologie. Wanneer wij het begrip 'religiewetenschap' als een overkoepelende term voor het zojuist geschetste proces gebruiken, kan er inderdaad sprake zijn van een ver-religiewetenschappelijking van de theologie. Volgens mij is dit proces irreversibel.

(Prof. Dr. Jean-Pierre Wils is decaan van de Faculteit der Religiewetenschappen van de Radboud Universiteit Nijmegen en hoogleraar Cultuurtheorie van de moraal, in het bijzonder in relatie met religie; Postbus 9103,6500 HD Nijmegen, j.p.wils@rs.ru.nl) 